\title{
REVITALISASI BANGUNAN TRADISIONAL RUMAH TingGal SEbagai HomestaY Dengan Pendekatan Adaptive Reuse Di Jagalan, Kotagede, Yogyakarta
}

\author{
Sisca Pramudya W, Ana Hardiana, Fauzan Ali Ikhsan \\ Program Studi Arsitektur \\ Fakultas Teknik \\ Universitas Sebelas Maret Surakarta \\ Email : pramudyasisca@gmail.com
}

\begin{abstract}
The sustainability for cultural heritage is a vital thing for present time and future. Recently, traditional house which is a javanese cultural heritage is slowly gone in Jagalan, Kotagede. Homestay in jagalan kotagede as a living museum which has a characteristic of cultural properties area has changed. The change is because of the necessity of a modern living which can not adapt to the old culture, economic necessity, and also eathquake in Jogja in 2006 go along the dull of Jagalan, Kotagede area characteristics. As Jagalan characteristics seems arousing little interest, it makes Jagalan loses heritage spirit and also leads to the unorganized local people. These are due to the economical, social and political matters. Thus, the effort to achieve harmony will be done, including area planning, traditional home stay building, local art, culinary road characteristics, Jagalan potential and adaptive side to the earthquake effect. The official announcement of "Jagalan Tlisih" by Sultan Hamengku Buwono X will be able to make everyone realize that the sustainability of cultural heritage is important. Jagalan Village should be supported by maintaining the potential within, in order to accomplish the realization of cultural tourism village. moreover, traditional building which is counted as potential legacy needs to be preserved and maintained. The maintenance is by revitalizing, to revive and to restore. Adaptive concepts is a way to build an object and environment so that when these aspects are combined they will be able to work together and create new thing without losing identity of their own. The preservation is applied by taking advantage from the traditional house to be a homestay. Moreover, homestay will be a new function in the form of traditional building to support Jagalan Village which has heritage value to fulfill the goal as a tourism destination. Furthermore, Jagalan area will be local based homestay along with adaptive people within its function as cultural tourism village. The new function is one of Adaptive Reuse as a dynamic revitalization responses from spatial, physic, and style aspect which can stands alone and revive its environment.
\end{abstract}

Keywords: Adaptive, Homestay, House, Revitalizing, Traditional

\section{PENDAHULUAN}

Ketika gempa bumi terjadi pada hari World Monuments Fund (WMF) yang berada di New York, Amerika Serikat menetapkan kawasan budaya Kotagede yang berada di wilayah Kota Yogyakarta menjadi salah satu dari 100 situs budaya di dunia yang paling terancam mengalami kepunahan khususnya sebagai akibat dari gempa bumi 27 Mei 2006 (Antara:12/06/07). Berdasarkan beberapa perubahan yang ada di Kotagede, banyak potensi bangunan tradisional Jawa, namun mulai hilang seperti halnya di Kampung Jagalan.
Kebutuhan akan kehidupan moderen yang tidak mampu mengadaptasi budaya lama, kebutuhan ekonomi hingga gempa Yogya tahun 2006 mengiringi pudarnya karakteristik kawasan Jagalan, Kotagede (Unesco House, 2007).

Konservasi rumah tradisional sebagai homestay mengambil kawasan percontohan di RW 3. Revitalisasi menjawab permasalahan bahwa konservasi tidak menolak adanya perubahan, bukan merupakan keinginan atau kebutuhan perseorangan atau minoritas, tidak menghalangi pengembangan kota atau kawasan. Melalui revitalisasi bangunan 
tradisional rumah tinggal sebagai homestay justru mendukung adanya fungsi baru yang adaptive tanpa merusak nilai dan dapat mendukung pengembangan kawasan yang melingkupinya sebagai kampung wisata pusaka. Selain itu, dapat memperkenalkan identitas dengan budaya dan kesenian yang ada di Jagalan dengan mengadaptasikan apa yang menjadi keasliannya pada keadaan yang sekarang. Dalam perancangannya, pemilihan rumah tinggal yang akan direvitalisasi sangat penting. Selain itu keputusan mempertahankan dan merubah pada objek, sistem struktur yang adaptive dengan kondisi kawasan serta integrasi dalam sebuah kawasan sehingga dapat menjawab permasalahan konsep perencanaan dan perancangan revitalisasi bangunan tradisional rumah tinggal sebagai homestay di Jagalan, Kotagede, Yogyakarta dengan pendekatan Adaptive Reuse.

\section{METODE}

Penggabungan dari hasil identifikasi kedua analisa sebelumnya yaitu mengidentifikasi penggunaan rumah tinggal, diantaranya pelaku kegiatan, jenis kegiatan, pola kegiatan, dan organisasi ruang serta menerjemahkan secara sistematik kebutuhan para pengguna homestay rumah tinggal tradisional dan fasilitasnya ke dalam persyaratan fungsi dan kebutuhan ruang baru, persyaratan besaran ruang serta program ruang baru dalam revitalisasi. Proses tersebut menganalisa masalah spasial (pemanfaatan ruang lama terhadap ruang baru), fisik (struktur) dan gaya (style) dalam revitalisasi rumah tinggal tradisional. Selain itu juga integrasi rumah tinggal tradisional dengan kawasan.

\section{ANALISIS}

A. Analisis Lokasi

Analisis dilakukan menggunakan metode scoring dengan dasar pertimbangan aspek yang mendukung revitalisasi homestay dikawasan pusaka seperti pada Tabel 1. Dari analisis, diperoleh lokasi yang terpilih adalah Jagalan RW 3.

Tabel 1. Analisis Pemilihan Lokasi

\begin{tabular}{llllll}
\hline RW/ASPEK & 1 & 2 & 3 & 4 & 5 \\
\hline $\begin{array}{l}\text { Rumah } \\
\text { tradisional }\end{array}$ & 10 & 8 & 10 & 9 & 9 \\
Revitalisasi & $\mathrm{v}$ & - & $\mathrm{v}$ & - & - \\
Kuliner & 6 & 6 & 9 & 4 & 6 \\
$\begin{array}{l}\text { Pengrajin } \\
\text { Kesenian }\end{array}$ & 8 & 7 & 6 & 4 & 4 \\
$\begin{array}{l}\text { Kemudahan } \\
\text { akses }\end{array}$ & 8 & 7 & 8 & 6 & 6 \\
$\begin{array}{l}\text { Kelengkapan } \\
\text { fasilitas }\end{array}$ & 8 & 7 & 9 & 6 & 6 \\
\begin{tabular}{l} 
Nilai \\
\hline
\end{tabular} & 40 & 35 & 43 & 29 & 31 \\
\hline
\end{tabular}

B. Pemilihan Rumah Tinggal Tradisional untuk Homestay

Pemilihan rumah tinggal untuk homestay berdasarkan beberapa aspek tujuannya supaya rumah tinggal tradisional yang akan dirancang benarbenar mendukung dan potensial. Potensi pada rumah tinggal seperti pada Gambar 1.

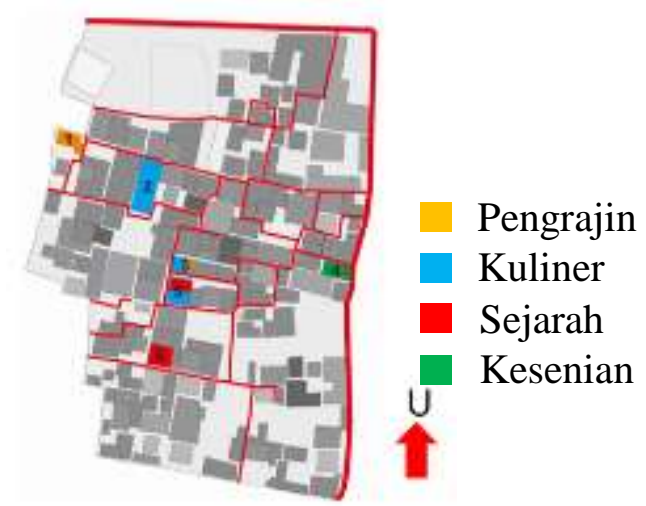

Gambar 1. Persebaran Rumah Tinggal

Dari proses analisis dihasilkan terpilihnya 4 rumah sebagai objek revitalisasi yaitu:

1. Pak Yanto (nomor 1 sebagai rumah pengrajin perak)

2. Ibu Esti (nomor 2 sebagai rumah kuliner)

3. Pak Herlan (nomor 4 sebagai rumah kesenian gamelan) 
4. Ibu Naryo (nomor 6 sebagai rumah perjuangan)

C. Peruangan

Analisa peruangan bertujuan untuk mengetahui pola kegiatan yang ada pada Homestay seperti Gambar 2 dengan dasar pertimbangan sebagai berikut.

1. Ruang-ruang eksisting

2. Pelaku kegiatan

3. Kegiatan pemilik

4. Kegiatan homestay

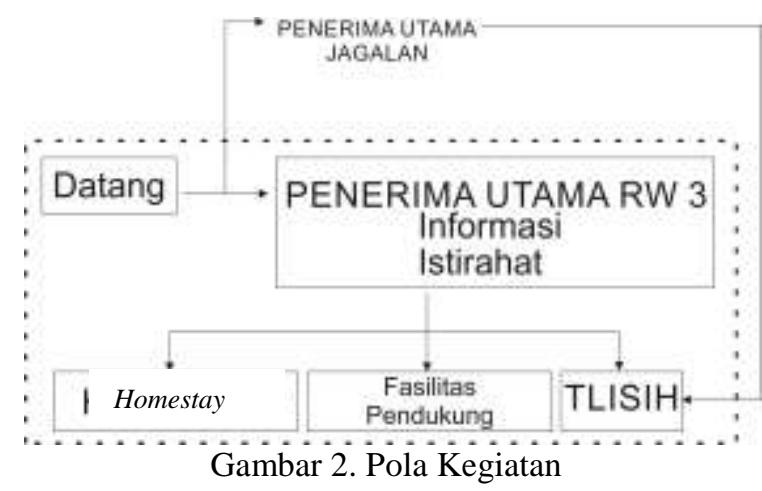

Tabel 2.Kebutuhan Ruang

\begin{tabular}{|c|c|c|}
\hline PELAKU & KEGIATAN & PERUANGAN \\
\hline \multirow[t]{3}{*}{$\begin{array}{l}\text { Pengun- } \\
\text { jung } \\
\text { Tamu } \\
\text { homestay }\end{array}$} & Datang & $\begin{array}{l}\text { Hall penerima } \\
\text { utama } \\
\text { Parkir } \\
\text { Resepsionis }\end{array}$ \\
\hline & Menginap & $\begin{array}{l}\text { R.tidur } \\
\text { R.makan } \\
\text { Dapur } \\
\text { R.produksi/ R. } \\
\text { kesenian } \\
\text { R.santai } \\
\text { KM/WC } \\
\text { Mushola }\end{array}$ \\
\hline & Tlisih & R.diskusi \\
\hline \multirow[t]{2}{*}{$\begin{array}{l}\text { Pemilik } \\
\text { homestay }\end{array}$} & $\begin{array}{l}\text { Mengelola } \\
\text { homestay }\end{array}$ & $\begin{array}{l}\text { Resepsionis } \\
\text { homestay }\end{array}$ \\
\hline & Daily & $\begin{array}{l}\text { R.tidur } \\
\text { R.makan } \\
\text { Dapur } \\
\text { R.produksi/ R. } \\
\text { kesenian } \\
\text { R.santai } \\
\text { KM/WC } \\
\text { Mushola } \\
\text { R.keluarga }\end{array}$ \\
\hline
\end{tabular}

Kebutuhan peruangan yang dibutuhkan dalam pemenuhan wadah homestay dan tlisih terlihat seperti pada Tabel 2.

D. Analisis Pendekatan Adaptive Reuse Analisis pendekatan Adaptive Reuse merupakan penerapan aspek konsep Adaptive Reuse dalam perencanaan pada Gambar 3.

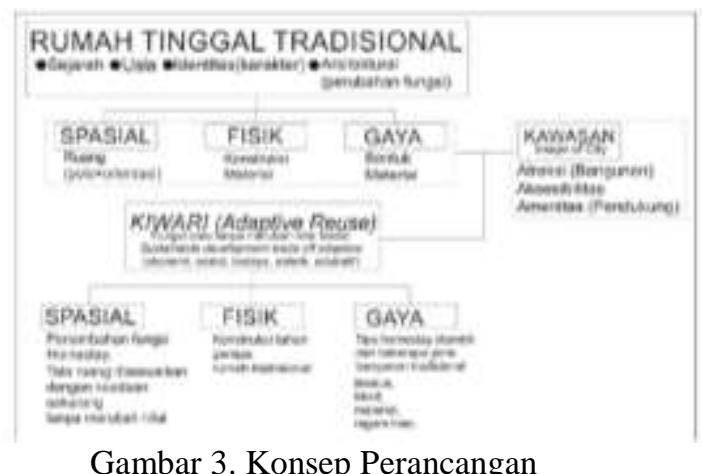

E. Analisis Rumah Tradisional untuk

Homestay

1. Rumah Pak Yanto

a. Spasial

Rumah joglo dengan perak sebagai kerajinan di rumah ini memberi

nilai bagi rumah joglo. Rumah Pak Yanto saat ini sudah tidak ditinggali oleh pemiliknya. Berikut adalah analisa perubahan ruang rumah Pak Yanto sebagai rumah pengrajin perak berdasarkan ruang eksisting, kegiatan, dan nilai ruang rumah tradisional Jawa yang dianalisis seperti pada Lampiran 1.

Berdasarkan analisa, ruang-ruang di rumah Pak Yanto kurang mewadahi kebutuhan ruang homestay, sehingga dirancang penambahan ruang secara vertikal sesuai nilai ruang rumah tradisional Jawa.

b. Fisik

Elemen fisik yang mendukung berdirinya bangunan rumah tinggal tersebut masih menggunakan kayu karena rumah tradisional Jawa sangat lekat dengan material kayu. Beberapa ruang di rumah Pak Yanto sudah tidak sesuai dengan 
nilai ruang rumah Jawa, seperti pada pendhapa Gambar 4 yang memiliki nilai ruang terbuka justru menggunakan dinding kayu tertutup.

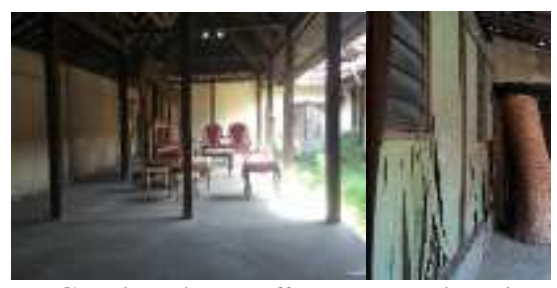

Gambar 4. Pendhapa Rumah Pak Yanto

Terjadi beberapa kerusakan seperti pada sambungan dan dinding sehingga memerlukan perbaikan dan perkuatan serta teknik penyambungan material struktur konstruksi pada lantai 1 dan 2.

c. Gaya

Gaya dan motif tradisional Jawa masih lekat di rumah joglo ini. Tanpa ukiran yang banyak, gebyok dan kayu masih menggambarkan tradisional pada rumah perak seperti pada Gambar 5.

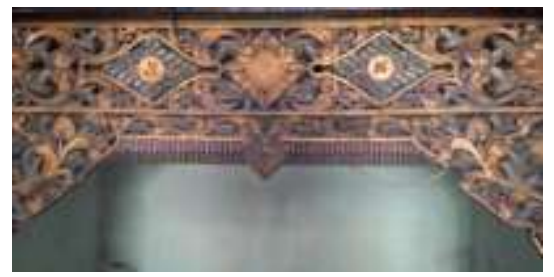

Gambar 5. Motif dan Gaya Rumah Pak Yanto

2. Rumah Ibu Esti

a. Spasial

Rumah Ibu Esti merupakan rumah joglo yang dahulunya dibuat oleh orang kalang sehingga banyak orang menyebutnya rumah kalang. Namun pada dasarnya terdapat 2 rumah joglo di rumah Ibu Esti. Ruang di rumah joglo tersebut sudah tidak sesuai dengan nilai ruang rumah Jawa. Lampiran 2 adalah analisa perubahan peruangan rumah Ibu Esti sebagai rumah kuliner. Pada rumah Ibu Esti direncanakan penambahan ruang secara vertikal karena perwadahan untuk kegiatan homestay tidak mencukupi.

b. Fisik

Pada saat gempa, rumah Ibu Esti mengalami renovasi pada pendhapa. Kerusakan struktur menjadi hal yang diperhatikan berkaitan dengan respon terhadap getaran. Oleh karenanya diperlukan sistem struktur yang tepat sebagai konsep struktur untuk mengkombinasikan struktur lama lantai 1 dan struktur baru lantai 2 .

c. Gaya

Rumah ini mempunyai detail arsitektur yang diterapkan pada konsul dari besi, jendela dan pintu yang tinggi, pintu kupu tarung yakni pintu dengan dua daun yang membuka ke luar atau ke dalam dengan material kayu berwarna hijau dan kuning coklat seperti pada Gambar 6.

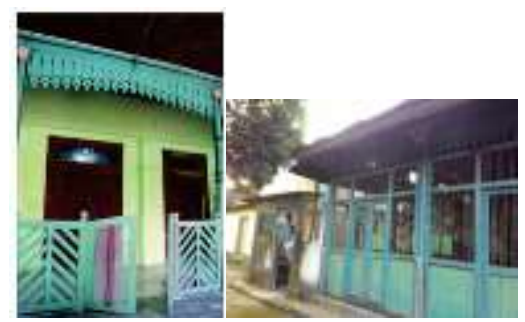

Gambar 6. Motif dan Gaya Rumah Ibu Esti

3. Rumah Pak Herlan

a. Spasial

Rumah Ibu Naryo merupakan rumah joglo perjuangan yang memiliki cerita sejarah yang kuat. Tata massa rumah Pak Herlan merupakan tatanan rumah tradisional Jawa yang masih lengkap yaitu terdapat pendhapa dan ndalem. Rumah utama Pak Herlan mengalami penambahan ruang di sisi timur gandhok untuk kamar menginap para pedagang sebelum gempa 2006. Namun saat ini ruang tersebut kosong. Rumah 
Pak Herlan mendapat bantuan dari JRF untuk renovasi pendhapa, dan sebagian berasal dari swadaya masyarakat. Berikut adalah analisa perubahan ruang rumah Pak Herlan sebagai rumah seni gamelan yang dijelaskan pada Lampiran 3.

b. Fisik

Pada saat gempa, pendhapa milik Pak Herlan rubuh dan direnovasi kembali dengan struktur yang sama. Dibutuhkan struktur baru yang tepat untuk mendukung penambahan ruang secara vertikal. Struktur yang tepat adalah perlakuan struktur yang dapat menggabungkan 2 struktur lama dan baru dengan material yang berbeda yaitu dinding batu bata dan kayu pada lantai 2.

c. Gaya

Sama seperti bangunan joglo lainnya, rumah Pak Herlan masih mempertahankan gaya tradisionalnya yang terlihat pada dinding gebyok dan konsol. Pada bangunan tambahannya sudah mengacu pada bangunan moderen yang masif dengan dinding batu bata sehingga diperlukan desain baru yang selaras dengan bangunan tradisional Jawa rumah Pak Herlan yang lama.

\section{Ibu Naryo}

a. Spasial

Pada gempa 2006, bagian belakang rumah ini (omah mburi) mengalami kerusakan dan mendapat bantuan perbaikan oleh pemerintah setempat. Rumah ini kini hanya dihuni oleh Rahdiningsih bersama anak bungsunya. Banyak ruang-ruang yang kini telah beralih fungsi sesuai dengan kebutuhan pemiliknya. Adanya fungsi baru sebagai homestay, maka analisa perubahan ruang rumah Ibu Naryo adalah seperti pada Lampiran 4.

b. Fisik

Pada saat gempa, terjadi kerusakan pada sambungan-sambungan kayu di rumah Ibu Naryo seperti konsol, dinding, dan balok. Adanya kerusakan tersebut membutuhkan perbaikan sekaligus sistem struktur yang baru dalam merespon penambahan ruang baru secara vertikal untuk perwadahan kegiatan homestay.

\section{c. Gaya}

Sebagian besar ornamen ukiran berupa motif tanaman rambat yang dikenal dengan sebutan lung-lungan pada istilah Jawa. Hal yang menarik adalah ukiran pada gebyok yang mengaplikasikan motif saton (berarti satu) yang biasanya lebih sering diaplikasikan untuk motif ukir pengisi daun pintu pada Gambar 7.

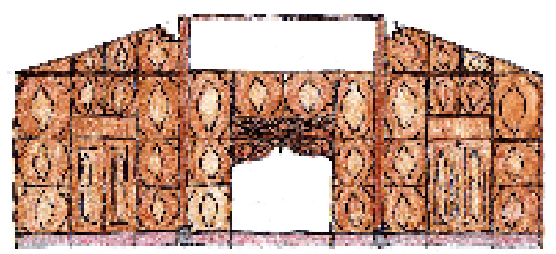

Gambar 7. Motif dan Gaya Rumah Ibu Naryo

F. Analisis Pengolahan Kawasan

Fasilitas-fasilitas yang ada di kampung menjadi sebuah potensi yang dapat dinikmati pengunjung saat tlisih.

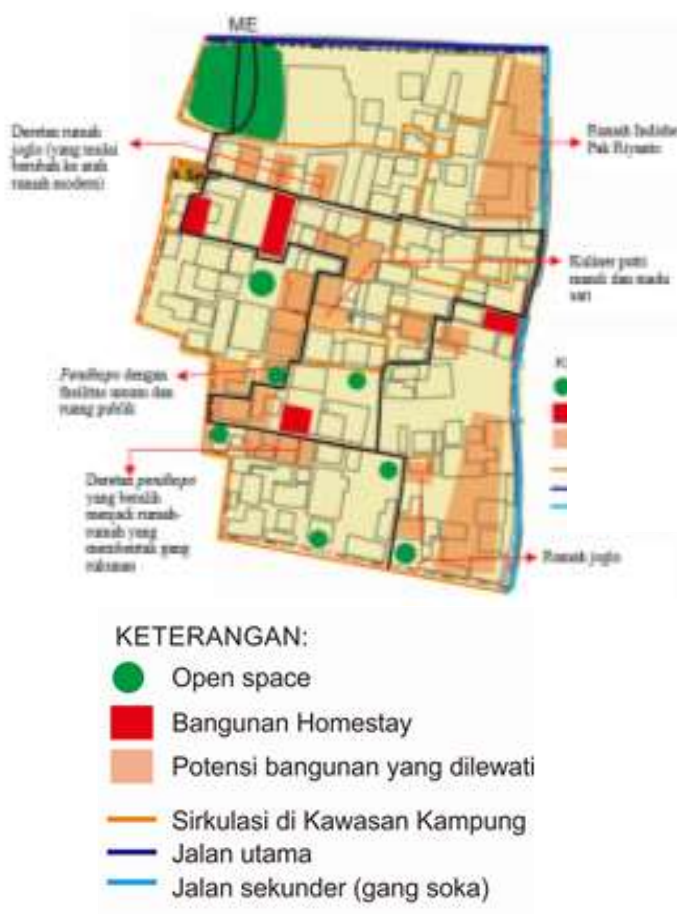

Gambar 8. Analisis Integrasi Kawasan 
Dari potensi yang ada di Kampung Jagalan RW 3 seperti potensi homestay, bangunanbangunan, ruang-ruang berkumpul dan sirkulasi membentuk suatu kawasan yang terintegrasi dengan titik-titik simpul, akses, pencapaian dan elemen kawasan yang bersinergi dalam sirkulasi gang yang berkarakter sempit seperti pada Gambar 9 dan menghasilkan konsep seperti Gambar 8.

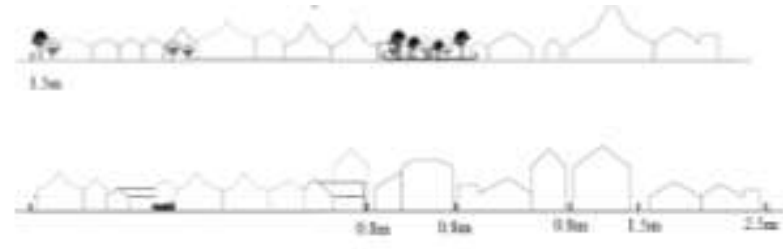

Gambar 9. Potongan Gang Kampung

\section{KESIMPULAN (KONSEP DESAIN)}

Konsep rancangan revitalisasi rumah tinggal tradisional adalah dengan memberikan fungsi baru sebagai homestay yang adaptive dari aspek spasial, fisik dan gaya serta terintegrasi dalam satu kawasan yang membentuk ruang hidup dengan karakter kampung wisata pusaka di Kampung Jagalan, Kotagede. Desain kawasan pada Gambar 14 dan objek rumah tinggal pada Gambar 15.

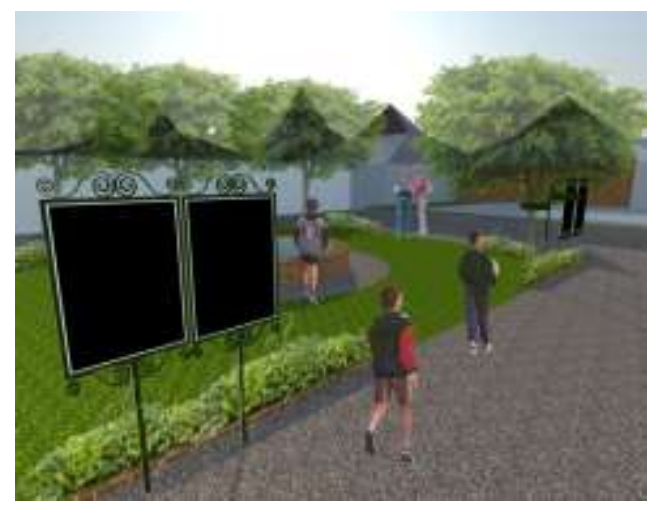

Gambar 14. Open Space Kawasan

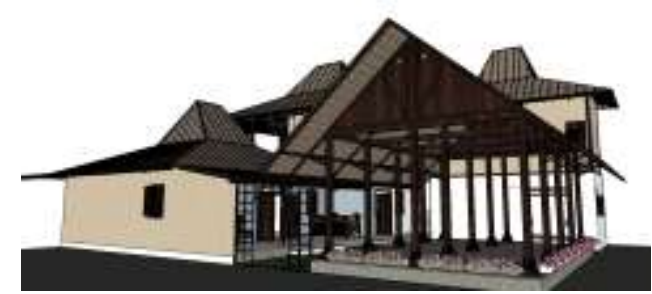

Gambar 15. Rumah Pengrajin Perak Pak Yanto

\section{REFERENSI}

Jogja Heritage Society. 2007, Homeowner's Conservation Manual.

Surat kabar Antara:12/06/07 